\title{
UK prevalence of underlying conditions which increase the risk of severe COVID-19 disease: a point prevalence study using electronic health records
}

Jemma L. Walker ${ }^{1,2,3}$, Daniel J. Grint ${ }^{1,2}$, Helen Strongman², Rosalind M. Eggo², Maria Peppa 1,2, Caroline Minassian², Kathryn E. Mansfield², Christopher T. Rentsch², lan J. Douglas², Rohini Mathur², Angel Y. S. Wong ${ }^{2}$, Jennifer K. Quint ${ }^{4}$, Nick Andrews ${ }^{1,2,3}$, Jamie Lopez Bernal ${ }^{1,3}$, J. Anthony Scott ${ }^{1,2}$, Mary Ramsay ${ }^{1,3}$, Liam Smeeth ${ }^{1,2}$ and Helen I. McDonald ${ }^{1,2^{*}}$ (D)

\begin{abstract}
Background: Characterising the size and distribution of the population at risk of severe COVID-19 is vital for effective policy and planning. Older age, and underlying health conditions, are associated with higher risk of death from COVID-19. This study aimed to describe the population at risk of severe COVID-19 due to underlying health conditions across the United Kingdom.

Methods: We used anonymised electronic health records from the Clinical Practice Research Datalink GOLD to estimate the point prevalence on 5 March 2019 of the at-risk population following national guidance. Prevalence for any risk condition and for each individual condition is given overall and stratified by age and region with binomial exact confidence intervals. We repeated the analysis on 5 March 2014 for full regional representation and to describe prevalence of underlying health conditions in pregnancy. We additionally described the population of cancer survivors, and assessed the value of linked secondary care records for ascertaining COVID-19 at-risk status.

Results: On 5 March 2019, 24.4\% of the UK population were at risk due to a record of at least one underlying health condition, including $8.3 \%$ of school-aged children, $19.6 \%$ of working-aged adults, and $66.2 \%$ of individuals aged 70 years or more. $7.1 \%$ of the population had multimorbidity. The size of the at-risk population was stable over time comparing 2014 to 2019, despite increases in chronic liver disease and diabetes and decreases in chronic kidney disease and current asthma. Separately, 1.6\% of the population had a new diagnosis of cancer in the past $5 \mathrm{y}$.

(Continued on next page)
\end{abstract}

\footnotetext{
* Correspondence: helen.mcdonald@Ishtm.ac.uk

'NIHR Health Protection Research Unit (HPRU) in Immunisation, London, UK

${ }^{2}$ London School of Hygiene \& Tropical Medicine, Keppel Street, London

WC1E 7HT, UK

Full list of author information is available at the end of the article
}

(c) The Author(s). 2021 Open Access This article is licensed under a Creative Commons Attribution 4.0 International License, which permits use, sharing, adaptation, distribution and reproduction in any medium or format, as long as you give appropriate credit to the original author(s) and the source, provide a link to the Creative Commons licence, and indicate if changes were made. The images or other third party material in this article are included in the article's Creative Commons licence, unless indicated otherwise in a credit line to the material. If material is not included in the article's Creative Commons licence and your intended use is not permitted by statutory regulation or exceeds the permitted use, you will need to obtain permission directly from the copyright holder. To view a copy of this licence, visit http://creativecommons.org/licenses/by/4.0/ The Creative Commons Public Domain Dedication waiver (http://creativecommons.org/publicdomain/zero/1.0/) applies to the data made available in this article, unless otherwise stated in a credit line to the data. 


\begin{abstract}
(Continued from previous page)
Conclusions: The population at risk of severe COVID-19 (defined as either aged $\geq 70$ years, or younger with an underlying health condition) comprises 18.5 million individuals in the UK, including a considerable proportion of school-aged and working-aged individuals. Our national estimates broadly support the use of Global Burden of Disease modelled estimates in other countries. We provide age- and region- stratified prevalence for each condition to support effective modelling of public health interventions and planning of vaccine resource allocation. The high prevalence of health conditions among older age groups suggests that age-targeted vaccination strategies may efficiently target individuals at higher risk of severe COVID-19.
\end{abstract}

Keywords: Prevalence, Risk factors, COVID-19, Electronic health records, United Kingdom

\section{Background}

The burden of mortality from COVID-19 rises steeply with age [1]. This is due to a combination of age itself, and the prevalence of underlying health conditions. Both age and underlying health conditions are independently associated with severe COVID-19 outcomes, including hospitalisation and mortality [2-5]. Many of the relevant underlying health conditions are also more common at older ages, and people with underlying health conditions account for the majority of COVID-19-related hospital and intensive care admissions [6]. This is reflected in United Kingdom (UK) national guidance describing individuals at moderate or high risk of severe COVID-19 (Table 1), which is based on age and underlying health conditions [7].

Characterising the size and distribution of the population at risk of severe COVID-19 is vital for effective policy and planning in response to the COVID-19 pandemic [9]. Age- and region-specific prevalence of atrisk groups are key to predicting mortality and managing pressure on hospital inpatient and intensive care services across the country. Numbers of school-aged children and working-aged adults at risk are important for reopening local schools and workplaces. Current international and UK national guidance advise that individuals at high risk of death from COVID-19 due to age or underlying health conditions should be a priority for COVID-19 vaccination [10, 11]. Vaccination planning requires at-risk population size for vaccine numbers, and age and regional distribution for modelling impact on regional transmission, since vaccine response typically decreases with older age [12].

Worldwide, modelling based on the Global Burden of Disease (GBD) study suggests that approximately one in five individuals have a health condition that increases risk of COVID-19 [13]. National prevalence studies of COVID-19 at-risk groups are rare. Large household surveys suggest that a third of adults in the United States, and between a third and a half of adults in Brazil, have at least one risk factor for COVID-19 (based on age $\geq 65$ years, or underlying health conditions for younger adults) $[14,15]$. A previous study estimated that at least
8.4 million individuals in the UK were at risk, but included only a subset of relevant health conditions [16]. Universal healthcare with an electronic health records system offers an opportunity for precise and representative estimation of at-risk prevalence in the UK, which may both support UK policy-making and offer a comparison with national GBD-based modelling estimates to aid in interpretation of GBD-based estimates internationally.

This study aimed to quantify the size, composition, and distribution of the population at risk of severe COVID-19 across the UK in March 2019, using electronic health records to define at-risk status based on all underlying conditions in UK national guidance.

\section{Methods}

\section{Data sources}

We conducted a point prevalence study among the UK general population using the Clinical Practice Research Datalink (CPRD) GOLD dataset, an anonymised sample of electronic health records from primary care practices across the UK [17]. The dataset includes diagnoses recorded using Read codes, primary care prescribing, and results of tests ordered in primary care. Data validity has been shown to be high [18]. The UK has universal healthcare, and the sample of the population who are in CPRD GOLD was found to be nationally representative by age and sex in March 2011: we re-assessed representativeness in 2019 in a sensitivity analysis [17].

Secondary care (hospital) data linkage is available for approximately 75\% of CPRD GOLD-registered individuals in England, based on practice-level consent. For patients admitted to hospital, the Hospital Episode Statistics Admitted Patient Care dataset records diagnoses using International Classification of Diseases ICD-10 codes, and procedures such as chemotherapy using Classification of Interventions and Procedures OPCS-4 codes [19].

The CPRD Pregnancy Register uses validated algorithms, combining information across the primary care 
Table 1 COVID-19 moderate- and high-risk groups in national guidance [7] compared to the at-risk population study definition

\begin{tabular}{|c|c|}
\hline $\begin{array}{l}\text { OVID-19 moderate- and high-risk population definitions in national guidance for } \\
\text { igland [7] }\end{array}$ & Study definition \\
\hline $\begin{array}{l}\text { Anyone aged } 70 \text { years or older (regardless of medical conditions) } \\
\text { is defined as at moderate risk. }\end{array}$ & \multirow{2}{*}{$\begin{array}{l}\text { The study definition of the at-risk population for all ages } \\
\text { comprised individuals with any of the underlying health } \\
\text { conditions in national guidance, incorporating high risk } \\
\text { groups as indicated. } \\
\text { Detailed inclusion criteria for each condition were based } \\
\text { on national guidance defining influenza clinical risk group } \\
\text { to reflect risk of respiratory infection [8]. }\end{array}$} \\
\hline $\begin{array}{l}\text { Among individuals aged less than } 70 \text { years, people at moderate } \\
\text { risk from coronavirus infection include people who: } \\
\text { - have a lung condition that's not severe (such as asthma, } \\
\text { chronic obstructive pulmonary disease, emphysema or bronchitis) }\end{array}$ & \\
\hline
\end{tabular}

condition (such as cystic fibrosis, severe asthma or severe chronic

obstructive pulmonary disease)

- have heart disease (such as heart failure)

- have diabetes

- have chronic kidney disease

- have liver disease (such as hepatitis)

- have a condition affecting the brain or nerves (such as Parkinson's

disease, motor neurone disease, multiple sclerosis or cerebral palsy)

- have a condition that means they have a high risk of getting

infections

o high risk have a condition that means they have a very high

risk of getting infections (such as SCID or sickle cell)

o high risk have blood or bone marrow cancer (such as

leukaemia, lymphoma or myeloma)

- are taking medicine that can affect the immune system (such

as low doses of steroids)

o high risk are taking medicine that makes them much more likely

to get infections (such as high doses of steroids or

immunosuppressant medicine)

o high risk have had an organ transplant

o high risk are having chemotherapy or antibody treatment for

cancer, including immunotherapy

o high risk are having an intense course of radiotherapy

(radical radiotherapy) for lung cancer

o high risk are having targeted cancer treatments that can

affect the immune system (such as protein kinase inhibitors or

PARP inhibitors)

o high risk have had a bone marrow or stem cell transplant in

the past 6 months, or are still taking immunosuppressant medicine

- are very obese (a BMl of 40 or above)

- are pregnant

o high risk have a serious heart condition and are pregnant

The prevalence of pregnancy was estimated separately from the general at-risk population.

record such as antenatal scans, expected delivery dates, and deliveries, terminations and miscarriage records, to date and characterise pregnancies in CPRD GOLD [20].

\section{Index dates}

Our primary analysis index date was 5 March 2019 for up-to-date national prevalence estimates. CPRD GOLD coverage peaked in 2014, when it included approximately 7\% of the UK population: by 2019 the dataset was smaller and did not cover all regions in England. Since the dataset in 2014 therefore offered greater power than 2019, and full regional representation across England, we repeated point prevalence estimates for 5 March 2014 as a sensitivity analysis.

Pregnancy was described for the index date of 5 March 2014 only, not 5 March 2019, since the latest Pregnancy Register update was in February 2018.

\section{Study population}

The study population comprised individuals aged 2-100 years with a current registration and a record meeting CPRD quality criteria (acceptable patient record and practice up to standard) in CPRD GOLD, with at least 1 y's prior registration to allow recording of underlying conditions [21]. Eligibility started on the latest of: 1 January 2019, second birthday, a year after registration, or practice meeting CPRD quality standards. Eligibility ended at the earliest of: 5 March 2019, hundredth birthday, death, leaving the practice, or last data collection from the practice. Individuals with any time eligible between 1 January and 5 March were included in the main analysis of point prevalence on 5 March to increase study power, with a sensitivity analysis limited to individuals active in the dataset on 5 March 2019.

For pregnancy, the study population comprised women aged 11-49 years. As pregnancy is transient, 
women were required to be registered in the dataset on 5 March 2014, rather than any time between 1 January and 5 March 2014.

\section{Definition of at-risk population}

In national guidance, all individuals aged $\geq 70$ years are considered at moderate risk (Table 1) [7]. Since agespecific population estimates are readily available, the primary analysis for this study defined at-risk status based on underlying health conditions alone, rather than age. An additional analysis estimated the size of the atrisk population including all individuals aged $\geq 70$ years.

We defined the COVID-19 at-risk population as individuals with at least one underlying health condition conferring moderate or high risk of severe COVID-19 according to national guidance (Table 1). Namely: any history of chronic respiratory disease (excluding asthma), heart disease, kidney disease, neurological conditions such as multiple sclerosis, diabetes mellitus; or current asthma, severe obesity, or immunosuppression; assessed on the index date [7].

Underlying conditions were defined using diagnoses, height and weight measurements, test results, and prescriptions recorded in primary care for the main analysis. Pregnancy status was ascertained from the CPRD Pregnancy Register (Supplementary Table 1, Additional File 1). Individuals with no recorded body mass index were included in the analysis, categorised as having no evidence of severe obesity. For analysis using linked secondary care data, diagnoses and procedures recorded in secondary care were additionally ascertained from ICD-10 and OCPS-4 codes respectively.

Multimorbidity was defined as more than one condition among the following domains: asthma or other chronic respiratory disease; chronic heart disease; chronic kidney disease; chronic liver disease; chronic neurological disease; diabetes; or immunosuppression (including individuals with dysplenia and organ transplant recipients).

Cancer survivors have an increased risk of COVID-19 mortality but non-haematological cancer survivors are only included in current COVID-19 guidance if receiving immunosuppressing treatment (Table 1) [2]. Separately to the study at-risk definition we described prevalence of any new cancer diagnosis in the past one and five years, as cancer survivors may be at increased risk of COVID-19 related death [2].

\section{Statistical analysis}

Point prevalence estimates of the at-risk population and each underlying condition on 5 March 2019 were calculated per 100,000 with binomial exact 95\% confidence intervals, for each nation in the UK. The at-risk population prevalence was stratified by sex and age, categorised in 5-year bands except 2-9 years and 90-99 years. Prevalence estimates for the at-risk population and each condition were stratified by age and region, separately and in combination. Prevalence values with fewer than five individuals were suppressed to preserve confidentiality.

For additional analysis estimating the size of the atrisk population including all individuals aged $\geq 70$ years, the at-risk prevalence among individuals aged 2-69 years was age-standardised in 5-year bands, and added to the population aged $\geq 70$ years, using mid-2019 national population estimates [22]. Comparison of prevalence in 2014 to 2019 was stratified by region to account for the change in regional representation of the dataset over time. The point prevalence of pregnancy and underlying health conditions was estimated among women aged 11-49 years on 5 March 2014. Prevalence estimates with and without linked secondary care records were compared among individuals at practices in England which had consented to data linkage.

\section{Sensitivity analyses}

CPRD GOLD was nationally representative by age and sex in March 2011 [17]. To update this assessment, the 2019 study population was compared to mid-2019 national population estimates, and 2019 at-risk prevalence estimates directly age-standardised in five-year bands using mid-2019 population estimates for each nation [22].

The main analysis included individuals eligible for any period of time between 1 January and 5 March 2019. Individuals who left CPRD between 1 January and 5 March would not subsequently have had new diagnoses recorded, which could underestimate point prevalence on 5 March. As a sensitivity analysis, at-risk prevalence was estimated with the study population restricted to individuals who were still registered in CPRD on 5 March 2019.

All analysis was conducted using STATA 16 MP.

\section{Results}

Characteristics of the study population

The 2019 study population included 2,706,053 individuals: 990,939 (36.6\%) in England, 801,352 in Scotland, 708,670 in Wales and 205,092 in Northern Ireland (Table 2). Approximately half (50.2\%) were female. The study included 359,412 individuals (13.3\%) aged $\geq 70$ years. There was some over-representation of 40-59year-olds compared to mid-2019 national population estimates for all four countries (Fig. 1).

In 2014, the dataset included 4,730,254 individuals: 2, 980,402 (63.0\%) in England, 810,169 (17.1\%) in Scotland, $730,563(15.4 \%)$ in Wales and 209,120 (4.4\%) in Northern Ireland (Supplementary Table 2, Additional File 1). Age and sex distributions were similar to 2019, with $50.3 \%$ female and $12.7 \%$ aged $\geq 70$ years. 


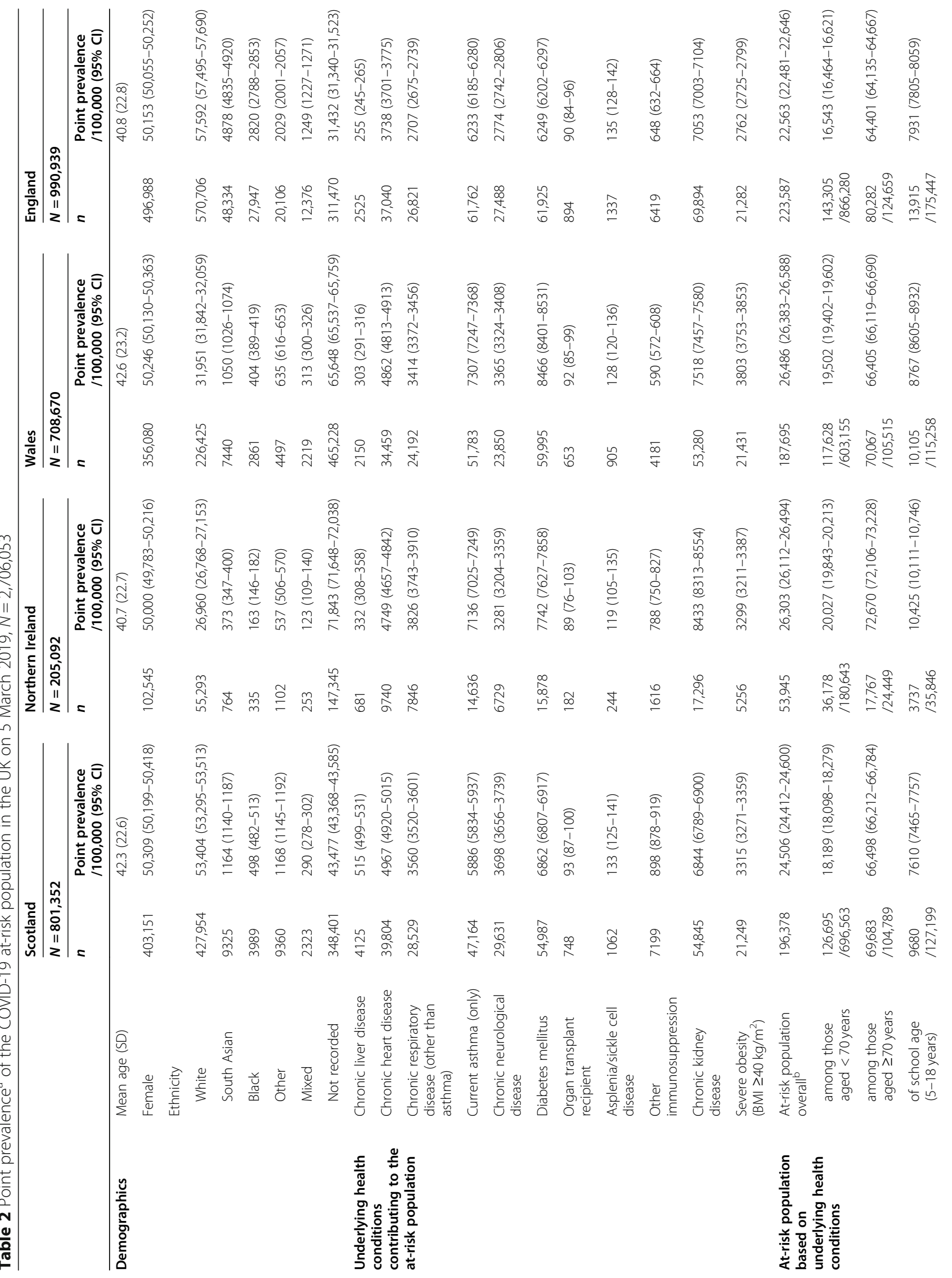




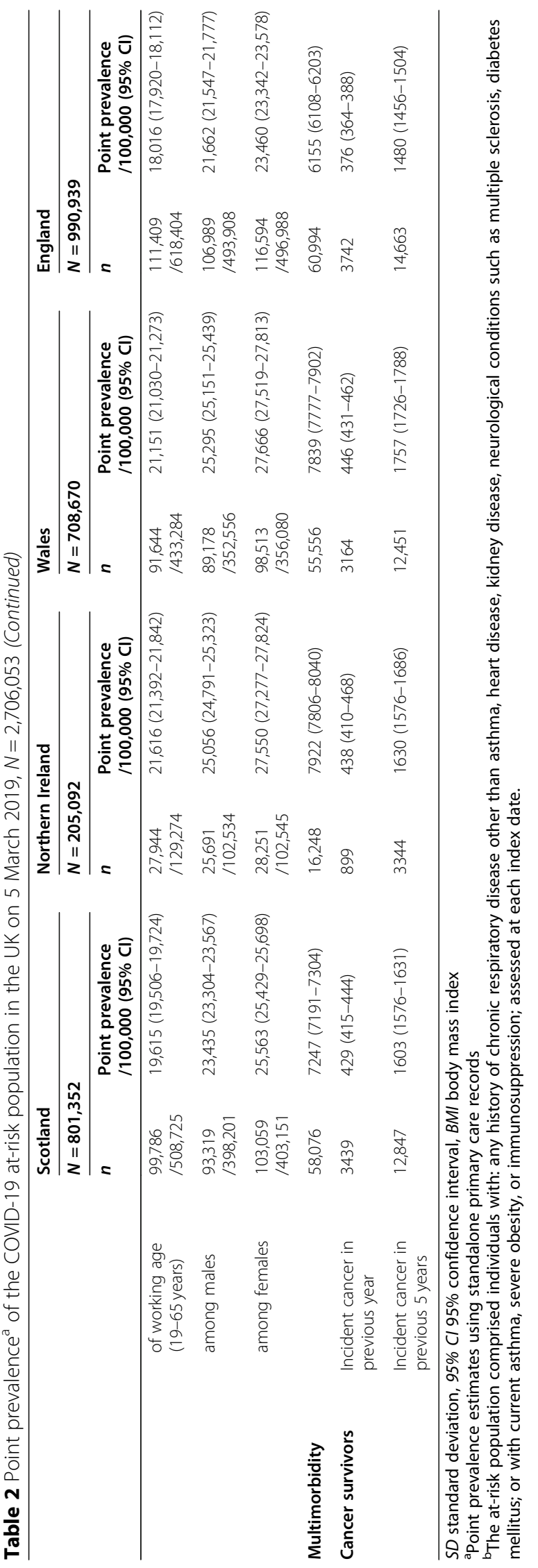




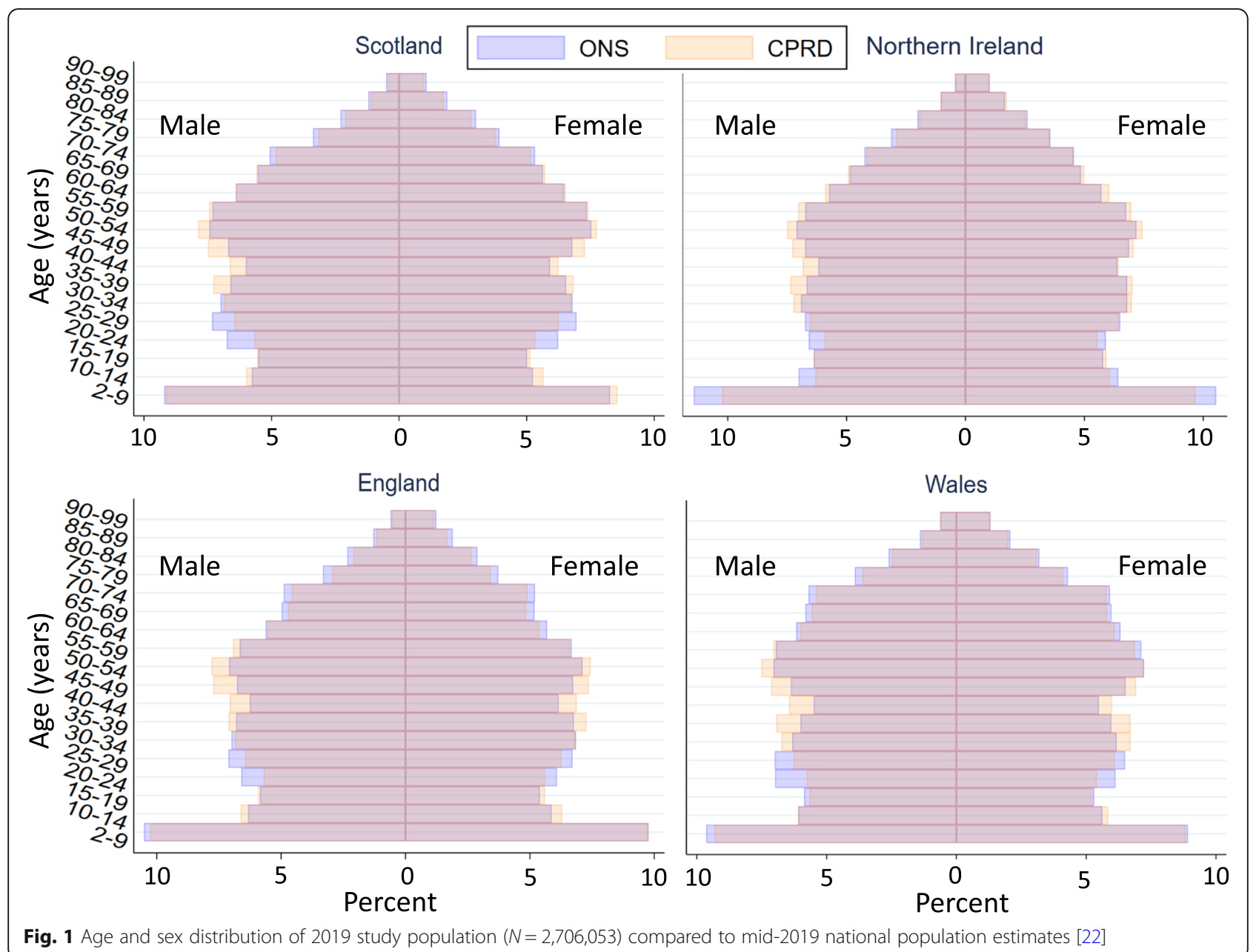

\section{COVID-19 at-risk population}

On 5 March 2019, 24.4\% (95\% CI 24.4-24.5) of the study population were at risk of severe COVID-19 due to underlying health conditions. National at-risk prevalence ranged from $22.6 \%$ in England to $26.5 \%$ in Wales (Table 2).

In a secondary analysis, the number of at-risk individuals based on current guidance including all individuals aged $\geq 70$ years was estimated at 18.5 million across the
UK, of whom 9.53 million (95\% CI 9.52-9.53) were aged $<70$ years (Table 3 ).

\section{Composition by underlying health conditions}

The commonest conditions across the UK were chronic kidney disease (7.2\%), diabetes mellitus (7.1\%), asthma (6.5\%) and chronic heart disease (4.5\%). Prevalence of each condition varied nationally, with chronic liver disease notably commoner in Scotland (Table 2).

Table 3 Estimated size of the 2019 UK at-risk population according to national guidance (either aged $\geq 70$ years, or younger with an underlying health condition)

\begin{tabular}{|c|c|c|c|c|c|}
\hline & \multicolumn{3}{|l|}{ Age 2 to 69 years } & \multirow{2}{*}{$\begin{array}{l}\text { Age } \geq 70 \text { years } \\
\text { Office for National } \\
\text { Statistics mid-2019 } \\
\text { population estimate }\end{array}$} & \multirow{2}{*}{$\begin{array}{l}\text { Estimated } \\
\text { total } \\
\text { number of } \\
\text { individuals } \\
\text { in the at-risk } \\
\text { population }\end{array}$} \\
\hline & $\begin{array}{l}\text { Age-standardised prevalence } \\
\text { of at least one underlying } \\
\text { health condition } / 100,000 \\
(95 \% \mathrm{Cl})\end{array}$ & $\begin{array}{l}\text { Office for National } \\
\text { Statistics mid-2019 } \\
\text { population estimate }\end{array}$ & $\begin{array}{l}\text { Estimated number of } \\
\text { individuals aged } 2-69 \text { years } \\
\text { with at least one underlying } \\
\text { health condition }(95 \% \mathrm{Cl})\end{array}$ & & \\
\hline Scotland & $18,046(17,956-18,137)$ & $4,615,093$ & $832,848(828,694-837,019)$ & 744,701 & $1,577,549$ \\
\hline Northern Ireland & $19,672(19,490-19,855)$ & $1,622,687$ & $319,213(316,266-322,182)$ & 224,851 & 544,064 \\
\hline Wales & $19,519(19,418-19,619)$ & $2,609,759$ & $509,389(506,776-512,011)$ & 480,234 & 989,623 \\
\hline England & $16,573(16,495-16,652)$ & $47,467,071$ & $7,866,870(7,829,660-7,904,217)$ & $7,556,976$ & $15,423,846$ \\
\hline
\end{tabular}


Multimorbidity was common, ranging from $6.2 \%$ in England to $7.9 \%$ in Northern Ireland: 7.1\% across the UK.

\section{Variation by age}

The proportion of at-risk individuals increased gradually with age from $5.1 \%$ of children aged $2-9$ years to a peak at $79.4 \%$ of those aged $85-89$ years in England before declining at older ages (Fig. 2). Similar age distributions were seen in each nation, and for each condition except current asthma, which peaked at age 10-14 years (Fig. 2).

The at-risk population comprised $18.1 \%$ of individuals aged $<70$ years (including $8.3 \%$ of school-aged children and $19.6 \%$ of working aged adults) and $66.2 \%$ of individuals aged $\geq 70$ years across the UK (Table 2 ).

\section{Variation by sex}

Overall, a higher proportion of women than men were at risk (Table 2), but the association varied with age, and men were more likely than women to be at risk from age 55 years upwards (Fig. 3; Supplementary Table 3, Additional File 1).

\section{Variation by region}

No individuals from the North East or East Midlands regions of England were included in 2019, whereas all regions were represented in 2014. London had the lowest proportion of the population considered at risk in both 2014 and 2019 (Fig. 4). The East of England, South Central and South East also had lower prevalence of at-risk individuals than Midlands or Northern regions in both 2014 and 2019. Regional patterns varied between underlying conditions (Supplementary Fig. 1, Additional File 1).

Prevalence estimates of the at-risk population and each condition stratified by age and region (separately and combined) on 5 March 2014 and 2019 are here: https://doi.org/10.17037/DATA.00001833

Differences between 2014 and 2019 prevalence estimates Compared to 2014, at-risk prevalence estimates in 2019 were $0.8 \%$ higher in Northern Ireland but lower in Scotland $(-0.5 \%)$, Wales $(-0.8 \%)$, and England $(-1.3 \%)$. When stratified by region within England (Fig. 4), at-risk prevalence increased from 2014 to 2019 for Yorkshire

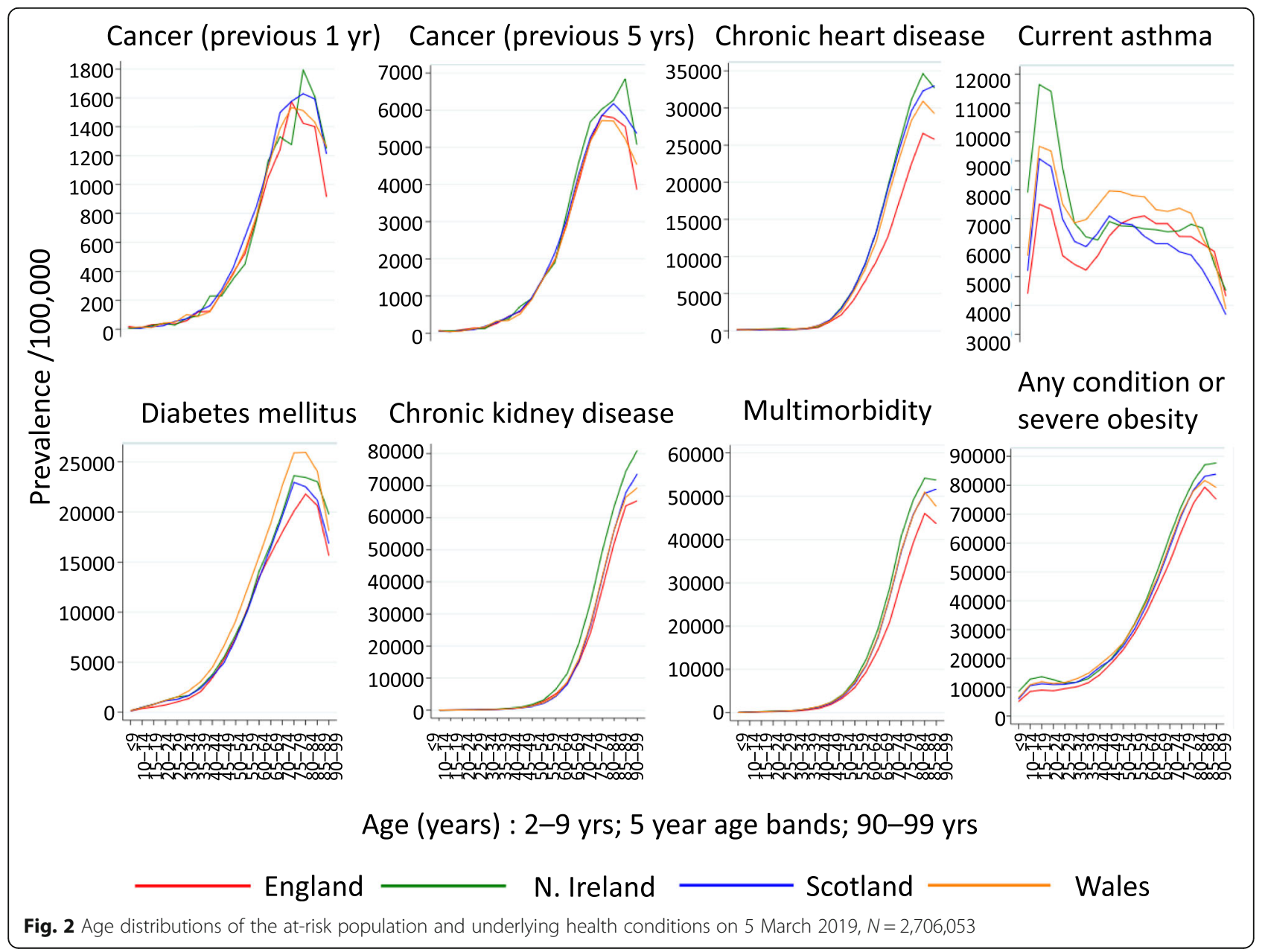




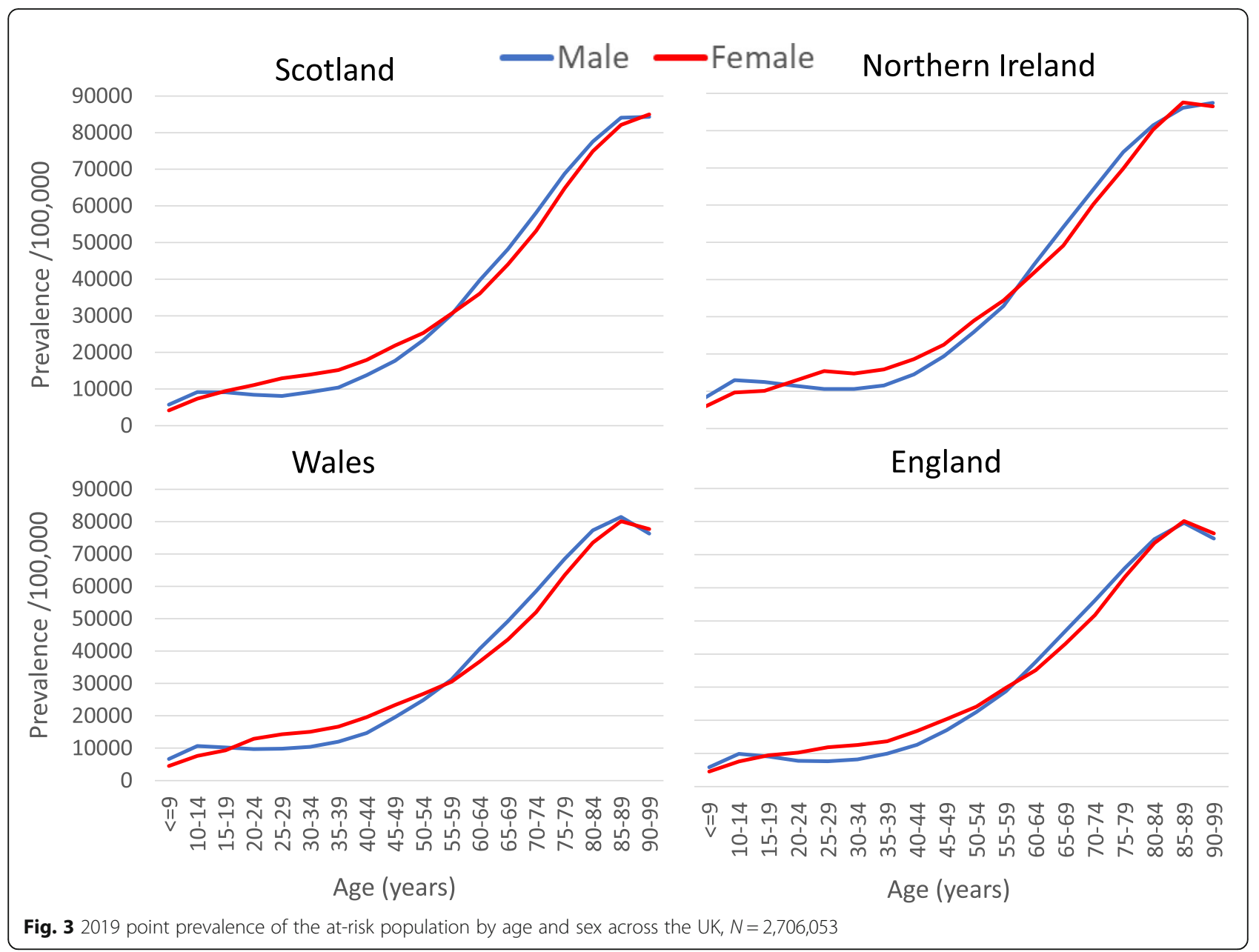

and the Humber and the West Midlands, and decreased in all other regions (excluding the North East and East Midlands, which were unavailable in the 2019 dataset), but no changes exceeded $1.9 \%$ difference.

For underlying conditions, absolute changes in UK prevalence estimates from 2014 to 2019 ranged from a $-0.9 \%$ decrease in chronic kidney disease to a $0.7 \%$ increase in diabetes mellitus (Supplementary Fig. 1, Additional File 1). The biggest relative increases were for chronic liver disease (+ 32.3\% from 2014 to 2019), diabetes $(+11.5 \%)$ and chronic respiratory disease other than asthma $(+11.4 \%)$. The largest relative falls were for chronic kidney disease $(-10.6 \%)$ and current asthma $(-6.0 \%)$.

\section{Cancer survivors}

On 5 March 2019, 0.4\% of the UK had incident cancer recorded within the previous year and $1.6 \%$ within the previous 5 y (Table 2).

\section{Pregnancy}

Among women aged 11-49 years on 5 March 2014, 2.1\% were pregnant, of whom $12.9 \%$ had a recorded health condition, compared to $14.5 \%$ of non-pregnant women (Table 4).

\section{Linked secondary care records}

At-risk prevalence based on standalone primary care records was similar among individuals with and without eligibility for data linkage. Linked secondary care records increased the estimated prevalence of the at-risk population in England by 1.8\% in both 2014 and 2019. The increase was greater among individuals $<70$ years than those $\geq 70$ years.

For underlying conditions, the greatest absolute changes in prevalence estimates were for multimorbidity, which increased from 6.5 to $7.6 \%$ in 2019 , and chronic heart disease, which increased from 4.0 to $5.3 \%$. The greatest relative increase was for chronic liver disease, which nearly doubled from 0.27 to $0.53 \%$ (Table 5).

\section{Sensitivity analyses}

Age-standardisation did not alter 2019 at-risk prevalence estimates (not presented). When the study population was restricted to individuals active on 5 March 2019, at- 


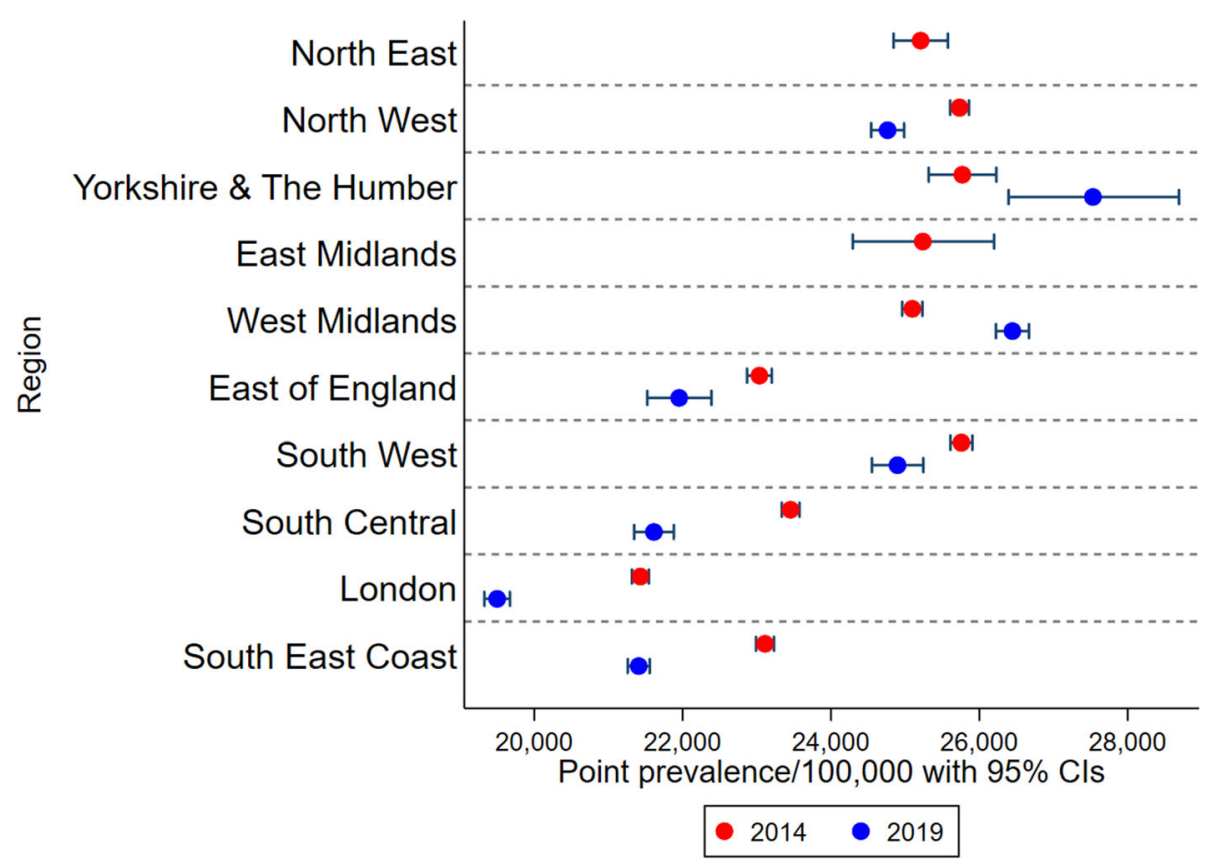

Fig. 4 Point prevalence of the England at-risk population by region comparing $2014(N=4,730,254)$ and $2019(N=2,706,053)$. The 2019 study population did not include any individuals in the North East or East Midlands regions; $x$-axis scale starts at 20,000/100,000

risk prevalence estimates fell by less than $1 \%$ (Supplementary Table 4, Additional File 1).

\section{Discussion}

This paper describes the size and distribution of the population at risk of severe COVID-19 based on clinical records from a large, nationally representative cohort across the UK.

On 5 March 2019, 24.4\% of the UK population were at higher risk than others of the same age due to underlying health conditions, including $8.3 \%$ of school-aged children, $19.6 \%$ of working-aged adults, and $66.2 \%$ of individuals aged $\geq 70$ years. The commonest conditions were chronic kidney disease, diabetes and asthma. Multimorbidity was common at $7.1 \%$. The size and regional distribution of the at-risk population was similar in 2014 and 2019, with lower prevalence in London and the South of England than Midlands or Northern regions. Separately, the $1.6 \%$ of the study population with a new diagnosis of cancer within the previous $5 \mathrm{y}$ may also be at increased risk of severe COVID-19 [2].

Including all individuals aged $\geq 70$ years, 18.5 million individuals in the UK would be considered moderate or high risk under current national guidance [7]. This is

Table 42014 prevalence $^{a}$ of pregnancy and underlying health conditions among women aged 11-49 years, $N=1,181,840$

\begin{tabular}{|c|c|c|c|c|c|c|c|c|}
\hline \multirow[b]{2}{*}{$\begin{array}{l}\text { Among all women aged } \\
11-49 \text { years }\end{array}$} & \multicolumn{2}{|c|}{ Scotland $N=205,542$} & \multicolumn{2}{|c|}{ Northern Ireland $N=55,559$} & \multicolumn{2}{|c|}{ Wales $N=177,412$} & \multicolumn{2}{|c|}{ England $N=743,327$} \\
\hline & $n$ & $\begin{array}{l}\text { Point prevalence } \\
/ 100,000(95 \% \mathrm{Cl})\end{array}$ & $n$ & $\begin{array}{l}\text { Point prevalence } \\
/ 100,000(95 \% \mathrm{Cl})\end{array}$ & $n$ & $\begin{array}{l}\text { Point prevalence } \\
/ 100,000(95 \% \mathrm{Cl})\end{array}$ & $n$ & $\begin{array}{l}\text { Point prevalence } \\
/ 100,000(95 \% \mathrm{Cl})\end{array}$ \\
\hline $\begin{array}{l}\text { Pregnant or any underlying } \\
\text { health condition }^{\mathrm{b}}\end{array}$ & 34,051 & $16,566(16,406-16,728)$ & 9234 & $16,620(16,311-16,932)$ & 31,140 & $17,552(17,376-17,730)$ & 117,680 & $15,832(15,749-15,915)$ \\
\hline $\begin{array}{l}\text { Any underlying health } \\
\text { condition }^{\mathrm{b}}\end{array}$ & 31,389 & $15,271(15,116-15,428)$ & 8317 & $14,970(14,674-15,269)$ & 28,733 & $16,196(16,024-16,368)$ & 102,121 & $13,738(13,660-13,817)$ \\
\hline Pregnant & 3067 & $1492(1440-1545)$ & 1069 & $1924(1811-2042)$ & 2834 & $1597(1540-1657)$ & 17,755 & $2389(2354-2424)$ \\
\hline
\end{tabular}

Prevalence of underlying health conditions, ${ }^{b}$ stratified by pregnancy status, among women aged 11-49 years

\begin{tabular}{|c|c|c|c|c|c|c|c|c|}
\hline $\begin{array}{l}\text { Pregnant with an underlying } \\
\text { health condition }^{\mathrm{b}}\end{array}$ & 405 & $13,205(12,026-14,455)$ & 152 & $14,219(12,179-16,458)$ & 427 & $15,067(13,769-16,458)$ & 2196 & $12,368(11,887-12,862)$ \\
\hline $\begin{array}{l}\text { Not pregnant, with an } \\
\text { underlying health condition }\end{array}$ & 30,984 & $15,303(15,146-15,460)$ & 8165 & $14,984(14,686-15,287)$ & 28,306 & $16,214(16,041-16,388)$ & 99,925 & $13,772(13,693-13,851)$ \\
\hline
\end{tabular}

b Underlying health conditions comprised: any history of chronic respiratory disease other than asthma, heart disease, kidney disease, neurological conditions such as multiple sclerosis, diabetes mellitus; or current asthma, severe obesity, or immunosuppression; assessed at each index date. 
Table 5 Prevalence estimates for England with and without linked secondary care data $(2014 N=1,802,468 ; 2019 N=744,496)$

\begin{tabular}{|c|c|c|c|c|c|c|c|c|}
\hline & \multicolumn{4}{|c|}{$\begin{array}{l}\text { Individuals in England eligible for secondary care data linkage in } \\
2014 N=1,802,468\end{array}$} & \multicolumn{4}{|c|}{$\begin{array}{l}\text { Individuals in England eligible for secondary care data linkage in } \\
2019 N=744,496\end{array}$} \\
\hline & \multicolumn{2}{|c|}{$\begin{array}{l}\text { Standalone primary care } \\
\text { data }\end{array}$} & \multicolumn{2}{|c|}{$\begin{array}{l}\text { Both primary and secondary } \\
\text { care data }\end{array}$} & \multicolumn{2}{|c|}{$\begin{array}{l}\text { Standalone primary care } \\
\text { data }\end{array}$} & \multicolumn{2}{|c|}{$\begin{array}{l}\text { Both primary and secondary } \\
\text { care data }\end{array}$} \\
\hline & $n$ & $\begin{array}{l}\text { Point prevalence } \\
/ 100,000(95 \% \mathrm{Cl})\end{array}$ & $N$ & $\begin{array}{l}\text { Point prevalence } \\
/ 100,000(95 \% \mathrm{Cl})\end{array}$ & $n$ & $\begin{array}{l}\text { Point prevalence } \\
/ 100,000(95 \% \mathrm{Cl})\end{array}$ & $n$ & $\begin{array}{l}\text { Point prevalence } \\
/ 100,000(95 \% \mathrm{Cl})\end{array}$ \\
\hline \multicolumn{9}{|c|}{ Underlying health conditions contributing to the at-risk population } \\
\hline Chronic liver disease & 4499 & $250(242-257)$ & 8104 & $450(440-459)$ & 2022 & $272(260-284)$ & 3941 & $529(513-546)$ \\
\hline Chronic heart disease & 87,217 & $4839(4807-4870)$ & 108,711 & $6031(5997-6066)$ & 29,399 & $3949(3905-3993)$ & 39,083 & $5250(5199-5300)$ \\
\hline $\begin{array}{l}\text { Chronic respiratory } \\
\text { disease }\end{array}$ & 53,358 & $2960(2936-2985)$ & 63,562 & $3526(3500-3553)$ & 21,345 & $2867(2829-2905)$ & 26,407 & $3547(3505-3589)$ \\
\hline Current asthma (only) & 125,548 & $6965(6928-7003)$ & 136,702 & 7584 (7546-7623) & 48,009 & $6449(6393-6505)$ & 53,030 & $7123(7065-7182)$ \\
\hline $\begin{array}{l}\text { Chronic neurological } \\
\text { disease }\end{array}$ & 60,482 & 3356 (3329-3382) & 69,932 & 3880 (3852-3908) & 21,818 & 2931 (2892-2969) & 26,284 & $3530(3489-3573)$ \\
\hline Diabetes mellitus & 110,144 & $6111(6076-6146)$ & 114,149 & $6333(6297-6369)$ & 48,461 & 6509 (6453-6566) & 50,760 & $6818(6761-6876)$ \\
\hline $\begin{array}{l}\text { Organ transplant } \\
\text { recipient }\end{array}$ & 1470 & $82(77-86)$ & 1732 & $96(92-101)$ & 707 & $95(88-102)$ & 838 & $113(105-120)$ \\
\hline $\begin{array}{l}\text { Asplenia/sickle cell } \\
\text { disease }\end{array}$ & 2545 & $141(136-147)$ & 2878 & $160(154-166)$ & 1089 & $146(138-155)$ & 1346 & $181(171-191)$ \\
\hline $\begin{array}{l}\text { Other } \\
\text { immunosuppression }\end{array}$ & 14,134 & $784(771-797)$ & 32,537 & 1805 (1786-1825) & 5035 & $676(658-695)$ & 7663 & $1029(1006-1052)$ \\
\hline Chronic kidney disease & 159,241 & 8835 (8793-8876) & 159,379 & 8842 (8801-8884) & 54,661 & 7342 (7283-7401) & 54,774 & $7357(7298-7417)$ \\
\hline $\begin{array}{l}\text { Severe obesity } \\
\left(\mathrm{BMI} \geq 40 \mathrm{~kg} / \mathrm{m}^{2}\right)\end{array}$ & 36,668 & $2581(2555-2607)$ & 36,668 & $2581(2555-2607)$ & 16,706 & $2898(2855-2942)$ & 16,706 & $2898(2855-2942)$ \\
\hline \multicolumn{9}{|l|}{ At-risk population ${ }^{a}$} \\
\hline At-risk population ${ }^{a}$ & 450,601 & $24,999(24,936-25,062)$ & 483,071 & $26,801(26,736-26,865)$ & 175,420 & $23,562(23,466-23,659)$ & 188,716 & $25,348(25,249-25,447)$ \\
\hline $\begin{array}{l}\text { among those aged } \\
<70 \text { years }\end{array}$ & 276,158 & $17,756(17,696-17,816)$ & 303,528 & $19,516(19,453-19,578)$ & 112,168 & $17,286(17,194-17,378)$ & 123,038 & $18,961(18,866-19,057)$ \\
\hline $\begin{array}{l}\text { among those aged } \\
\geq 70 \text { years }\end{array}$ & 174,443 & 70,579 (70,399-70,759) & 179,543 & $72,643(72,466-72,818)$ & 63,252 & $66,157(65,856-66,457)$ & 65,678 & $68,694(68,399-68,988)$ \\
\hline Multimorbidity & 133,803 & $7423(7385-7462)$ & 155,802 & 8644 (8603-8685) & 48,009 & 6449 (6393-6505) & 56,827 & 7633 (7573-7693) \\
\hline \multicolumn{9}{|l|}{ Cancer survivors } \\
\hline $\begin{array}{l}\text { Incident cancer in } \\
\text { previous year }\end{array}$ & 8343 & $463(453-473)$ & 10,680 & $593(581-604)$ & 2936 & 394 (380-409) & 3806 & $511(495-528)$ \\
\hline $\begin{array}{l}\text { Incident cancer in } \\
\text { previous } 5 \text { years }\end{array}$ & 31,195 & $1731(1712-1750)$ & 36,815 & $2042(2022-2063)$ & 11,708 & $1573(1544-1601)$ & 13,854 & $1861(1830-1892)$ \\
\hline
\end{tabular}

$95 \% \mathrm{Cl}, 95 \%$ confidence interval.

${ }^{a}$ The at-risk population comprised individuals with: any history of chronic respiratory disease other than asthma, heart disease, kidney disease, neurological conditions such as multiple sclerosis, diabetes mellitus; or with current asthma, severe obesity, or immunosuppression; assessed at each index date.

higher than a previous estimate of 8.4 million comprising $7.2 \%$ of men and $7.5 \%$ of women aged $30-69$ years, and $33 \%$ of men and $29 \%$ of women aged $\geq 70$ years [16]. Our estimates include additional conditions to cover the full national guidance [7]. There were also differences in ascertainment: for example, our diabetes prevalence estimate for ages 30-69 in England was 7.0\%, compared to $2.2 \%$ in the previous study [16] and $6.9 \%$ in the national Quality Outcomes Framework (QOF) [23]. This may be due to increases in diagnoses and recording of diabetes over time in our more recent study period of March 2019 (rather than 1997-2017) [16].

Our at-risk prevalence estimates were slightly lower than GBD-based estimates that $29.1 \%$ of the UK population had at least one underlying health condition increasing COVID-19 risk, or $28.1 \%$ when restricted to the same set of conditions by excluding cancers causing indirect immunosuppression and tuberculosis from GBDbased estimates [13]. This did not appear to be due to under-estimation of clustering due to multimorbidity in the GBD-based study, as the $9.2 \%$ multimorbidity prevalence modelled was higher than we observed even when using linked secondary care records. The difference was greatest among older age groups, and our finding that $19.6 \%$ of working-aged adults (19-65 years) were at risk is broadly comparable to the GBD-based estimate (for the same conditions) of $22.8 \%$ among those aged 15-64 years [13].

Our prevalence estimates are in line with national QOF diabetes and cancer monitoring, slightly higher than the more narrowly defined QOF chronic heart disease estimates [23], and consistent with previous UK 
studies of chronic kidney disease and asthma [24, 25]. The five-year trends of increasing diabetes and decreasing asthma prevalence are consistent with directions of change in a previous study of asthma [24], and QOF, although 2014 QOF diabetes prevalence was slightly higher at $6.2 \%$ in 2013/14 [23].

Linked secondary care records in England increased the estimated size of the at-risk population only modestly, but the estimated prevalence of chronic liver disease in 2019 nearly doubled from 0.27 to $0.53 \%$, and multimorbidity and chronic heart disease prevalence also increased. Our chronic liver disease prevalence estimate in England of 529/100,000 when supplemented with secondary care data is more consistent with previous national estimates of approximately $600 / 100,000$ for the UK than our lower estimate using primary care data alone [26]. Several studies of the associations between underlying health conditions and COVID-19 outcomes in England have used standalone primary care records to characterise underlying health conditions [3, 27]. Such studies may under-ascertain chronic liver disease, heart disease and multimorbidity, and thus underestimate associations of these conditions with COVID-19 outcomes. If the risk of severe COVID-19 differs between underlying health conditions, then their differential under-ascertainment in primary health records may bias estimates of associations of underlying health conditions with COVID-19 outcomes. Among women who were pregnant on 5 March 2014, 12.9\% were at risk due to an underlying health condition, compared to a third of the pregnant women admitted to hospital with COVID-19 [28]. While the pregnancy register has high sensitivity for livebirths, pregnancy losses may be under-recorded [20]. The $2.1 \%$ point prevalence estimate of pregnancy is perhaps low compared to a survey in which 591/5686 (10\%) of women aged 16-44 years in Britain reported a pregnancy ending in the previous year, although these are not easily comparable [29]. Caution is required in applying historical pregnancy estimates, as COVID-19 may affect family planning.

\section{Strengths and limitations}

To our knowledge, these are the first prevalence estimates of the full population at risk of severe COVID-19 across the UK according to national guidelines. Strengths include the large, nationally representative cohort, risk group definitions with detailed ascertainment tailored to risk of COVID-19, and quantification of the value of linked secondary care records.

Our definition of the at-risk population was based on UK national guidance [7]. Large national studies have found that the health conditions in national COVID-19 guidance are indeed associated with increased risk of COVID-19-related death, although the size of associations vary [2-4]. Older individuals have also been found to be at higher risk of severe COVID-19 than younger, independent of underlying health conditions [2-4]. However, understanding of the risk factors for severe COVID-19 is still evolving. To support policy and planning to adapt flexibly to future evidence of the associations of different underlying conditions with COVID-19 outcomes, we provide age- and region- stratified prevalence for each underlying condition separately, including separating asthma from other respiratory conditions $[27,30]$.

A key limitation is that UK-wide estimates rely on primary care records, which may miss undiagnosed conditions and under-ascertain conditions diagnosed in secondary care. Our analysis including linked secondary care records in England suggests that estimates of the overall size of the at-risk population are robust, but that the prevalence of multimorbidity, chronic heart disease and liver disease may be underestimated from primary care records. There is likely under-ascertainment of immunosuppressing cancer treatments even using secondary care records, which could be on a scale similar to the $1.6 \%$ of the population newly diagnosed with cancer within the previous year. Second, the 2019 estimates did not include all regions in England. Although the dataset remained nationally representative in terms of age and sex in 2019, and prevalence estimates of individual conditions were consistent with expectations, suggesting that national 2019 estimates are representative, regionally-stratified estimates in 2019 are incomplete. Prevalence estimates from 2014 include all regions but are less up-to-date, and differences from 2019 may reflect changes in prevalence and recording of conditions, and the CPRD GOLD population over time. Third, inclusion of individuals active in the dataset at any point between 1 January and 5 March could have resulted in some under-estimation of point prevalence on 5 March: sensitivity analysis suggested this was minimal. Finally, we were able to describe pregnancy in 2014 only, and pregnancy prevalence may be under-estimated.

\section{Conclusions}

We estimate that current national guidance on COVID19 risk groups encompasses 18.5 million individuals across the UK, a larger population than previously estimated. These national estimates broadly support the use of Global Burden of Disease modelled estimates and age-targeted vaccination strategies in other countries.

We found that $66.2 \%$ of individuals aged $\geq 70$ years had at least one recorded underlying condition, suggesting that an age-based approach to COVID-19 vaccination could efficiently target individuals at highest risk. Implementation of public health measures such as influenza 
vaccination generally achieve higher uptake when targeted on the basis of age rather than health conditions [31]. Age-based vaccination strategies may also be more feasible to implement in low-resource settings.

Our finding that $8.3 \%$ of school-aged children and $19.6 \%$ of working aged adults are in the at-risk population (as currently defined) emphasises the need to consider younger at-risk individuals in shielding guidance and when reopening schools and workplaces. The large number of children and younger adults with underlying conditions, who may nevertheless be at low absolute risk of severe COVID-19, supports vaccine strategies based on age- and condition-specific estimates of risk of severe COVID-19, rather than including individuals of any age with underlying conditions. We provide age-stratified prevalence for each condition to support effective vaccine resource allocation based on age and health conditions.

\section{Supplementary Information}

The online version contains supplementary material available at https://doi. org/10.1186/s12889-021-10427-2.

Additional file 1: Supplementary Table 1. Study definitions of underlying health conditions and pregnancy. Supplementary Table 2. Study population characteristics and point prevalence of the COVID-19 at-risk population on 5 March 2014 in the United Kingdom using standalone primary care data, $N=4,730,254$. Supplementary Table 3 . The atrisk population prevalence on 5 March 2019 stratified by age and sex. Supplementary Table 4. At-risk prevalence estimates on 5 March 2019 with and without individuals who left CPRD between 1st January and 5th March 2019. Supplementary Figure 1. Point prevalence of the at-risk group and contributing underlying health conditions by region on 5 March 2014 compared to 5 March 2019 (2019 does not include any individuals in the North East or East Midlands regions; $x$-axis scales vary by condition)

\section{Abbreviations}

UK: United Kingdom; GBD: Global Burden of Disease; CPRD GOLD: Clinical Practice Research Datalink GOLD; BMI: Body Mass Index; QOF: Quality Outcomes Framework

\section{Acknowledgements}

This work uses data provided by patients and collected by the NHS as part of their care and support.

\section{Authors' contributions}

MR, JLB, RME, JLW and HIM conceived the study. HIM, DJG, JLW, HS, RME, IJD, NA, JLB, JAS, and LS designed the study. HIM, JLW, DJG, JKQ, HS, MP, CM, KEM, CTR, IJD, RM, AYSW designed the study variable definitions. JLW and DJG led the data extraction and data analysis with data analysis by HS, MP, CM, KEM, CTR, IJD, WM, AYSW, and HIM. All authors contributed to interpretation of results. HIM, JLW and HS drafted the manuscript to which all authors contributed, revised critically and approved. All authors read and approved the final manuscript. HIM is the guarantor. The corresponding author (HIM) attests that all listed authors meet authorship criteria and that no others meeting the criteria have been omitted.

\section{Funding}

The study was funded by the National Institute for Health Research (NIHR) Health Protection Research Unit (HPRU) in Immunisation at the London School of Hygiene and Tropical Medicine in partnership with Public Health England (PHE). The views expressed are those of the authors and not necessarily those of the NHS, the NIHR, the Department of Health and Social
Care, or PHE. The corresponding author had full access to all the data in the study and had final responsibility for the decision to submit for publication. The study funder had no role in study design; in the collection, analysis, and interpretation of data; in the writing of the report; nor in the decision to submit the paper for publication.

\section{Availability of data and materials}

The data used for this study were obtained from the Clinical Practice Research Datalink (CPRD). All CPRD data are available via an application to the Independent Scientific Advisory Committee (see https://www.cprd.com/ Data-access). Data acquisition is associated with a fee and data protection requirements. This manuscript is supported by shared codelists used to define each condition, and estimates of the prevalence of the at-risk population and each underlying health condition, stratified by age and region (separately and combined) are available at https://doi.org/10.17037/DATA. 00001833

\section{Ethics approval and consent to participate}

Approval was received from the Independent Scientific Advisory Committee of the Medicines and Healthcare Products Regulatory Agency (ISAC number: 20_062A) and the Ethics Committee of the London School of Hygiene and Tropical Medicine (reference 21851). The ISAC protocol was made available to reviewers.

\section{Consent for publication}

Not applicable.

\section{Competing interests}

JLW, DJG, NA, JAS, LS, MR, HM received grants from the NIHR HPRU in Immunisation to support the submitted work. RME received grants from HDR UK (MR/S003975/1) and UK MRC (MC_PC 19065). JKQ reports grants and personal fees from $A Z$, grants from Asthma UK, grants and personal fees from $\mathrm{Bl}$, grants and personal fees from Bayer, grants and personal fees from Insmed, grants and personal fees from GSK, grants from The Health Foundation, grants from MRC, grants from British Lung Foundation, outside the submitted work; RM reports personal fees from AMGEN, outside the submitted work; JAS reports grants from National Institute for Health Research, during the conduct of the study; grants from MRC, grants from Wellcome Trust, grants from GAVI The Vaccine Alliance, grants from Bill \& Melinda Gates Foundation, outside the submitted work; LS reports grants from Wellcome, grants from MRC, grants from NIHR, grants from GSK, grants from BHF, grants from Diabetes UK, outside the submitted work; and Is a Trustee of the British Heart Foundation. The PHE Immunisation and Countermeasures Department provides vaccine manufacturers with postmarketing surveillance reports which the companies are required to submit to the UK Licensing authority in compliance with their Risk Management Strategy. A cost recovery charge is made for these reports.

\section{Author details}

${ }^{1} \mathrm{NIHR}$ Health Protection Research Unit (HPRU) in Immunisation, London, UK. ${ }^{2}$ London School of Hygiene \& Tropical Medicine, Keppel Street, London WC1E 7HT, UK. ${ }^{3}$ Public Health England, 61 Colindale Ave, London NW9 5EQ, UK. ${ }^{4}$ Imperial College London, South Kensington, London SW7 2BU, UK.

Received: 30 September 2020 Accepted: 11 February 2021

Published online: 11 March 2021

\section{References}

1. O'Driscoll M, Ribeiro Dos Santos G, Wang L, Cummings DAT, Azman AS, Paireau J, Fontanet A, Cauchemez S, Salje H. Age-specific mortality and immunity patterns of SARS-CoV-2. Nature. 2021;590(7844):140-5.

2. Williamson EJ, Walker AJ, Bhaskaran K, Bacon S, Bates C, Morton CE, Curtis HJ, Mehrkar A, Evans D, Inglesby P, Cockburn J, McDonald HI, MacKenna B, Tomlinson L, Douglas IJ, Rentsch CT, Mathur R, Wong AYS, Grieve R, Harrison D, Forbes H, Schultze A, Croker R, Parry J, Hester F, Harper S, Perera R, Evans SJW, Smeeth L, Goldacre B. Factors associated with COVID-19related death using OpenSAFELY. Nature. 2020;584(7821):430-6.

3. de Lusignan S, Dorward J, Correa A, Jones N, Akinyemi O, Amirthalingam G, Andrews N, Byford R, Dabrera G, Elliot A, Ellis J, Ferreira F, Lopez Bernal J, Okusi C, Ramsay M, Sherlock J, Smith G, Williams J, Howsam G, Zambon M, Joy M, Hobbs FDR. Risk factors for SARS-CoV-2 among patients in the 
Oxford Royal College of General Practitioners Research and Surveillance Centre primary care network: a cross-sectional study. Lancet Infect Dis. 2020; 20(9):1034-42

4. Clift AK, Coupland CAC, Keogh RH, Diaz-Ordaz K, Williamson E, Harrison EM, et al. Living risk prediction algorithm (QCOVID) for risk of hospital admission and mortality from coronavirus 19 in adults: national derivation and validation cohort study. BMJ. 2020;371:m3731.

5. Mudatsir M, Fajar J, Wulandari L, Soegiarto G, Ilmawan M, Purnamasari Y, et al. Predictors of COVID-19 severity: a systematic review and meta-analysis [version 1; peer review: 2 approved]. F1000Research. 2020;9(1107).

6. Docherty $A B$, Harrison EM, Green CA, Hardwick HE, Pius R, Norman $L$, et al. Features of 20133 UK patients in hospital with covid-19 using the ISARIC WHO clinical characterisation protocol: prospective observational cohort study. BMJ. 2020;369:m1985.

7. NHS. People at higher risk from coronavirus 2020 [26/06/2020]. Available from: https://web.archive.org/web/20200716054208/https://www.nhs.uk/ conditions/coronavirus-covid-19/people-at-higher-risk/whos-at-higher-riskfrom-coronavirus/.

8. Public Health England. Immunisation against Infectious Disease (the Green Book). Chapter 19: Influenza. https://www.gov.uk/government/publications/ influenza-the-green-book-chapter-19. Accessed 26 Feb 2021.

9. Jordan RE, Adab P. Who is most likely to be infected with SARS-CoV-2?. Lancet Infect Dis. 2020;20(9):995-6.

10. Department of Health and Social Care. JCVI: updated interim advice on priority groups for COVID-19 vaccination 2020 [updated 25 September 2020]. Available from: https://web.archive.org/web/20201002071610/https:// www.gov.uk/government/publications/priority-groups-for-coronaviruscovid-19-vaccination-advice-from-the-jcvi-25-september-2020/jcvi-updatedinterim-advice-on-priority-groups-for-covid-19-vaccination.

11. World Health Organization. Roadmap for prioritising population groups for vaccines against COVID-19 2020. https://www.who.int/news-room/q-a-deta il/coronavirus-disease-(covid-19)-vaccine-access-and-allocation. Accessed 26 Feb 2021.

12. Crooke SN, Ovsyannikova IG, Poland GA, Kennedy RB. Immunosenescence and human vaccine immune responses. Immun Ageing. 2019;16:25

13. Clark A, Jit M, Warren-Gash C, Guthrie B, Wang HHX, Mercer SW, et al. Global, regional, and national estimates of the population at increased risk of severe COVID-19 due to underlying health conditions in 2020: a modelling study. Lancet Glob Health. 2020;8(8):e1003-e1017.

14. Rezende LFM, Thome B, Schveitzer MC, Souza-Júnior PRB, Szwarcwald CL. Adults at high-risk of severe coronavirus disease-2019 (Covid-19) in Brazil. Rev Saude Publica. 2020;54:50.

15. Koma W, Neuman T, Claxton G, Rae M, Kates J, Michaud J. How many adults are at risk of serious illness if infected with coronavirus? Updated data. 2020 Available from: https://www.kff.org/coronavirus-covid-19/issue-brief/how-ma ny-adults-are-at-risk-of-serious-illness-if-infected-with-coronavirus/.

16. Banerjee A, Pasea L, Harris S, Gonzalez-Izquierdo A, Torralbo A, Shallcross L, et al. Estimating excess 1-year mortality associated with the COVID-19 pandemic according to underlying conditions and age: a population-based cohort study. Lancet. 2020;395(10238):1715-25.

17. Herrett E, Gallagher AM, Bhaskaran K, Forbes H, Mathur R, van Staa T, et al. Data resource profile: clinical practice research Datalink (CPRD). Int J Epidemiol. 2015;44(3):827-36.

18. Herrett E, Thomas SL, Schoonen WM, Smeeth L, Hall AJ. Validation and validity of diagnoses in the general practice research database: a systematic review. Br J Clin Pharmacol. 2010;69(1):4-14

19. Herbert A, Wijlaars L, Zylbersztejn A, Cromwell D, Hardelid P. Data Resource Profile: Hospital Episode Statistics Admitted Patient Care (HES APC). Int J Epidemiol. 2017:46(4):1093.

20. Minassian C, Williams R, Meeraus WH, Smeeth L, Campbell OMR, Thomas SL. Methods to generate and validate a pregnancy register in the UK clinical practice research Datalink primary care database. Pharmacoepidemiol Drug Saf. 2019;28(7):923-33.

21. Lewis JD, Bilker WB, Weinstein RB, Strom BL. The relationship between time since registration and measured incidence rates in the general practice research database. Pharmacoepidemiol Drug Saf. 2005;14(7): $443-51$.

22. Office for National Statistics. Population estimates for the UK, England and Wales, Scotland and Northern Ireland: mid-2019. 2020. Available from: https://www.ons.gov.uk/peoplepopulationandcommunity/populationa ndmigration/populationestimates/bulletins/annualmidyearpopulationestima tes/mid2019estimates.

23. Public Health England. Cardiovascular Disease, Diabetes and Kidney Disease 2020 [26/06/2020]. Available from: https://fingertips.phe.org.uk/profilegroup/cardiovascular-disease-diabetes-kidney-disease.

24. Bloom Cl, Saglani S, Feary J, Jarvis D, Quint JK. Changing prevalence of current asthma and inhaled corticosteroid treatment in the UK: populationbased cohort 2006-2016. Eur Respir J. 2019;53:4.

25. McDonald $\mathrm{HI}$. The epidemiology of infections among older people with diabetes mellitus and chronic kidney disease. London: London School of Hygiene \& Tropical Medicine; 2015.

26. Pimpin L, Cortez-Pinto H, Negro F, Corbould E, Lazarus JV, Webber L, et al. Burden of liver disease in Europe: epidemiology and analysis of risk factors to identify prevention policies. J Hepatol. 2018;69(3):718-35.

27. Williamson E, Walker AJ, Bhaskaran KJ, Bacon S, Bates C, Morton CE, et al. [Preprint] OpenSAFELY: factors associated with COVID-19-related hospital death in the linked electronic health records of 17 million adult NHS patients. medRxiv. 2020:2020.05.06.20092999.

28. Knight M, Bunch K, Vousden N, Morris E, Simpson N, Gale C, et al. Characteristics and outcomes of pregnant women admitted to hospital with confirmed SARS-CoV-2 infection in UK: national population based cohort study. BMJ. 2020:369:m2107.

29. Wellings K, Jones KG, Mercer CH, Tanton C, Clifton S, Datta J, et al. The prevalence of unplanned pregnancy and associated factors in Britain: findings from the third National Survey of sexual attitudes and lifestyles (Natsal-3). Lancet. 2013:382(9907):1807-16.

30. Halpin DMG, Faner R, Sibila O, Badia JR, Agusti A. Do chronic respiratory diseases or their treatment affect the risk of SARS-CoV-2 infection? Lancet Respir Med. 2020;8(5):436-8.

31. Public Health England. Surveillance of influenza and other respiratory viruses in the UK: Winter 2019 to 2020. 2020. Available from: https://assets. publishing.service.gov.uk/government/uploads/system/uploads/attachment data/file/895233/Surveillance_Influenza_and_other_respiratory_viruses_in_ the_UK_2019_to_2020_FINAL.pdfW.

\section{Publisher's Note}

Springer Nature remains neutral with regard to jurisdictional claims in published maps and institutional affiliations.
Ready to submit your research? Choose BMC and benefit from:

- fast, convenient online submission

- thorough peer review by experienced researchers in your field

- rapid publication on acceptance

- support for research data, including large and complex data types

- gold Open Access which fosters wider collaboration and increased citations

- maximum visibility for your research: over $100 \mathrm{M}$ website views per year

At $\mathrm{BMC}$, research is always in progress.

Learn more biomedcentral.com/submission 